\title{
Incidence, Risk Factors and Outcomes of Delayed-Onset Cytomegalovirus Disease in a Large Retrospective Cohort of Lung Transplant Recipients
}

\author{
Carlos A. Q. Santos ${ }^{1}$, Daniel C. Brennan ${ }^{2}$, Roger D. Yusen ${ }^{3}$, and Margaret A. Olsen ${ }^{1,4}$ \\ Daniel C. Brennan: dbrennan@dom.wustl.edu; Roger D. Yusen: ryusen@dom.wustl.edu; Margaret A. Olsen: \\ molsen@dom.wustl.edu \\ ${ }^{1}$ Division of Infectious Diseases, Department of Medicine, Washington University School of \\ Medicine, St. Louis, Missouri, United States of America \\ ${ }^{2}$ Division of Renal Diseases, Department of Medicine, Washington University School of Medicine, \\ St. Louis, Missouri, United States of America \\ ${ }^{3}$ Division of Pulmonary and Critical Care Medicine, Department of Medicine, Washington \\ University School of Medicine, St. Louis, Missouri, United States of America \\ ${ }^{4}$ Division of Public Health Sciences, Department of Surgery, Washington University School of \\ Medicine, St. Louis, Missouri, United States of America
}

\begin{abstract}
Background-Cytomegalovirus (CMV) replication and disease commonly occur in lung transplant recipients after stopping anti-CMV prophylaxis. The epidemiology of CMV disease is not well-studied given difficulties in assembling representative study populations with prolonged follow-up. We hypothesized that delayed-onset CMV disease (> 100 days post-transplant) occurs more commonly than early-onset CMV disease in lung transplant recipients, and is associated with an increased risk of death.
\end{abstract}

\begin{abstract}
Methods-We assembled a large cohort of lung transplant recipients using 2004 to 2010 ICD-9CM billing data from 3 Agency for Healthcare Research and Quality (AHRQ) State Inpatient Databases (SID), and identified demographics, comorbidities, CMV disease coded during hospital readmission and inpatient death. We used Cox proportional hazard multivariate analyses to assess for an independent association between delayed-onset CMV disease and death.
\end{abstract}

\footnotetext{
Address for correspondence: Carlos A. Q. Santos, MD; csantos@dom.wustl.edu; 660 S. Euclid Avenue, Campus Box 8051, St. Louis, Missouri, United States of America, 63110.

Disclosure: The authors have no conflicts to disclose.

Author's specific contributions to the work: Carlos A. Q. Santos - Participated in research design, performance of research, data analysis and writing of the paper; supported by the Washington University Institute of Clinical and Translational Sciences Multidisciplinary Clinical Research Career Development Program funded by National Institutes of Health grant KL2 TR000450; no conflicts of interest to disclose.

Daniel C. Brennan - Participated in research design, performance of research, data analysis and writing of the paper; no conflicts of interest to disclose.

Roger D. Yusen - Participated in research design and writing of the paper; no conflicts of interest to disclose.

Margaret A. Olsen - Participated in research design, performance of research, data analysis and writing of the paper; no conflicts of interest to disclose.
} 
Results-In the cohort of 1,528 lung transplant recipients from 12 transplant centers, delayedonset CMV disease occurred in 13.7\% ( $\mathrm{n}=210)$ and early-onset CMV disease occurred in 3.3\% $(\mathrm{n}=51)$. Delayed-onset CMV pneumonitis was associated with inpatient death $>100$ days posttransplant (aHR 1.6, 95\% CI 1.1-2.5), after adjusting for transplant failure/rejection (aHR 2.5, 95\% CI 1.5-4.1), bacterial pneumonia (aHR 2.8, 95\% CI 2.0-3.9), viral pneumonia (aHR 1.5, 95\% CI 1.1-2.1), fungal pneumonia (aHR 1.8, 95\% CI 1.3-2.3), single lung transplant (aHR 1.3, 95\% CI 1.0-1.7) and idiopathic pulmonary fibrosis (aHR 1.4, 95\% CI 1.0-1.8).

Conclusions-Delayed-onset CMV disease occurred more commonly than early-onset CMV disease among lung transplant recipients. These results suggest that delayed-onset CMV pneumonitis was independently associated with an increased risk of death.

\section{Introduction}

Cytomegalovirus (CMV) infection and disease commonly occur in lung transplant recipients 1,2 , and can be asymptomatic or manifest as CMV syndrome or tissue-invasive lung or gastrointestinal disease ${ }^{3-5}$. CMV infection has been demonstrated to be associated with an increased risk of acute allograft rejection 1, 6 and bronchiolitis obliterans syndrome (BOS) ${ }^{7-11}$. Because of its association with poor outcomes, preventive anti-CMV strategies in lung transplant recipients are utilized ${ }^{12}$, with the majority of transplant centers using antiCMV prophylaxis with oral valganciclovir or intravenous ganciclovir for 3 to 6 months. An international consensus committee convened in 2010 recommended at least 6 months of anti-CMV prophylaxis for CMV-seronegative lung transplant recipients that received lungs from CMV-seropositive donors (D+/R-) and 3 to 6 months of anti-CMV prophylaxis for CMV seropositive recipients $(\mathrm{R}+)^{13}$. A randomized controlled trial that demonstrated the superiority of 12 months over 3 months of valganciclovir prophylaxis in preventing CMV disease among $\mathrm{D}+\mathrm{R}$ - and $\mathrm{R}+$ lung transplant recipients ${ }^{14,15}$ supports even longer treatment.

Increasing the duration of anti-CMV prophylaxis can lead to delaying the onset of CMV disease in the absence of effective anti-CMV immunity 16,17 . It is unclear whether delayedonset CMV disease is similarly linked to poor outcomes as CMV disease that occurs earlier after lung transplantation, when the immunocompromised state can be most marked.

Researchers have had difficulty studying delayed-onset CMV disease since assembling large and representative study cohorts with prolonged follow-up is challenging. To understand the epidemiology of delayed-onset CMV disease among lung transplant recipients, we used data from the Agency for Healthcare Research and Quality Healthcare Cost and Utilization Project (AHRQ-HCUP) State Inpatient Databases (SID) of California, Florida and New York. These SID consist of demographic and billing data based on inpatient International Classification of Diseases, Ninth Revision, Clinical Modification (ICD-9-CM) coding with encrypted patient-level identifiers allowing identification of admissions within and across hospitals over time in a state. Presuming the administration of anti-CMV prophylaxis to D $+/ R$ - and $\mathrm{R}+$ patients for at least 3 months after lung transplantation ${ }^{12}$, we hypothesized that delayed-onset CMV disease (> 100 days post-transplant) occurs more commonly than early-

Transplantation. Author manuscript; available in PMC 2016 August 01. 
onset CMV disease, and delayed-onset CMV disease is associated with an increased risk of death compared to no delayed-onset CMV disease.

\section{Methods}

\section{Study design and patient population}

We performed a retrospective cohort study of adult ( $\geq 18$ years of age) lung transplant recipients (ICD-9-CM codes 33.50, 33.51, 33.52) who underwent transplantation from 2004 to 2010 in the California SID and 2006 to 2010 in the Florida and New York SID (total $\mathrm{n}=1,982$ ). We chose the cohort inception years to include 1 year of prior data to identify comorbidities, and obtain at least 1 year of follow-up data. We excluded patients who lived in states other than the one where transplantation was performed $(n=300)$ since the SID contain only hospitalizations that occur within a state and lung transplant recipients from out of state were likely to have missing follow-up. We also excluded patients who received another solid-organ transplant during the same hospitalization or underwent transplantation at a pediatric hospital as identified by the American Hospital Association (AHA) Annual Hospital Survey $(\mathrm{n}=12)$, or had coding for CMV disease within 1 year before lung transplantation or during the transplant hospitalization $(n=142)$. The final study population consisted of 1,528 lung transplant recipients. The study protocol was reviewed by the Institutional Review Board of Washington University in St. Louis and was exempted from Human Research Protection Office oversight.

\section{Demographic data, comorbidities and follow-up}

ICD-9-CM diagnosis and procedure codes used in this study are given in Table 1. Demographic characteristics of the study population were determined at the time of transplantation, comorbidities were identified using the Elixhauser classification ${ }^{18}$, and possible reasons for lung transplant and prior solid-organ transplantation were identified using codes in Table 1. Inpatient readmissions were identified using the encrypted patientlevel identifier. New-onset CMV disease coded during hospital readmission was identified and further characterized using diagnosis codes for CMV pneumonitis and hepatitis. There are no ICD-9-CM codes for CMV esophagitis, gastritis, enteritis or colitis. New-onset CMV disease was categorized as either early-onset $(<100$ days post-transplant) or delayed-onset ( $\leq 100$ days post-transplant). Other conditions identified at readmission were newly-coded transplant failure or rejection, clinical sepsis, hemodialysis, repeat solid-organ transplant during readmission, bacterial pneumonia, viral pneumonia and fungal pneumonia. There is no distinct ICD-9-CM code for BOS apart from the one used for transplant failure or rejection. Inpatient death was determined using the discharge status variable.

\section{Statistical analysis}

Descriptive statistics were used to describe the demographic and clinical characteristics of the study population. Potential risk factors for delayed-onset CMV disease and inpatient death coded during hospital readmission were analyzed using univariate and multivariate Cox proportional hazards modeling. In the analysis for risk factors for delayed-onset CMV disease, patients were censored at the time of repeat any solid-organ transplant, inpatient death or maximum follow-up (December 31, 2011). In the analysis for risk factors for 
inpatient death > 100 days post-transplant, patients were censored on December 31, 2011. Only patients who survived $>100$ days post-transplant and were not coded with CMV disease $\leq 100$ days post-transplant were included in the analysis for risk factors for delayedonset CMV disease and death. The proportional hazards assumption was evaluated for each variable using visual inspection of log-log survival curves and the correlation between Schoenfeld residuals for a particular covariate and the ranking of individual failure times ${ }^{19}$. Dummy variables for transplant center, state and year of transplant added to the models did not change the parameter estimates of the primary explanatory variables by more than $10 \%$, indicating no significant effect of clustering. Statistical significance was set at a p-value of $\leq$ 0.05. All analyses were performed using SAS version 9.2 (Cary, North Carolina).

\section{Results}

\section{Demographic and clinical characteristics}

The study population consisted of 1,528 adult lung transplant recipients from 12 transplant centers (Table 2). The median age at the time of transplant was 58 years, and $42 \%$ were female. Seventy-seven percent were white, $95 \%$ of patients lived in metropolitan centers, progressively more patients lived in ZIP codes with increasing median incomes by quartile, and private insurance companies accounted for $50 \%$ of the patients' expected primary payers. Thirty-four percent of the study population underwent single lung transplantation. Chronic obstructive pulmonary disease was the most common indication for lung transplant. Four percent of the recipients had a prior solid-organ transplant, of which $85 \%$ were lung transplant. Thirty-eight percent of patients had hypertension and 33\% had diabetes mellitus. The median duration of follow-up was 3.0 years, with an interquartile range of 1.6 to 4.7 years.

\section{New-onset CMV disease coded during hospital readmission}

New-onset CMV disease was identified in $17 \%$ of the study population, with a median time to onset of 253 days after lung transplantation (interquartile range 126 - 516 days) (Table 3). Early-onset CMV disease occurred in 3.3\% and delayed-onset CMV disease occurred in $14 \%$ of recipients. Among the delayed-onset cases of CMV disease, $48 \%$ occurred $>365$ days post-transplant. Twenty-five percent of delayed-onset CMV disease was coded as CMV pneumonitis, and there were no identified cases of CMV hepatitis. The remaining 75\% not coded as CMV pneumonitis may have had asymptomatic viremia, CMV syndrome or tissue-invasive gastrointestinal disease, which do not have specific ICD-9-CM codes. Transplant failure or rejection was coded in $76 \%$ of hospital readmissions with new-onset CMV disease. Thirty-five percent of lung transplant recipients coded with CMV disease subsequently died during follow-up, with a median time to death of 290 days. Among patients coded with CMV pneumonitis, $51 \%$ subsequently died during follow-up, with a median time to death of 233 days.

Analysis of risk factors for delayed-onset CMV disease using univariate Cox proportional hazard (Table 4) found a 34\% increased risk of delayed-onset CMV disease for recipients that had a single lung transplant, compared to double or unspecified lung transplant ( $\mathrm{p}$ value $=0.039$ ). Analyses did not identify other risk factors. 


\section{Other first-time conditions coded during hospital readmission}

Coding for transplant failure or rejection was found in $77 \%$ of lung transplant patients, with median time to onset of 26 days post-transplant (interquartile range $10-141$ days). There is no specific code for BOS. Bacterial pneumonia was identified in 55\% of patients, with median time to onset of 74 days post-transplant (interquartile range $14-344$ days). Viral pneumonia was identified in $7.7 \%$ of patients, with median time to onset of 388 days posttransplant (interquartile range $221-795$ days), and fungal pneumonia was identified in $8.9 \%$ of patients, with median time to onset of 326 days post-transplant (interquartile range $128-877$ days). Transplant failure or rejection was coded in $74 \%, 89 \%$ and $82 \%$ of hospitalizations coded for first-time bacterial pneumonia, viral pneumonia and fungal pneumonia respectively.

\section{Inpatient death}

Inpatient death was identified in $27 \%$ of the lung transplant cohort on follow-up, with approximately $6.3 \%$ occurring $\leq 100$ days post-transplant and $20 \%$ occurring $>100$ days post-transplant (Table 3). Commonly co-occurring conditions during hospitalizations wherein death was coded included transplant failure or rejection (81\%), bacterial pneumonia (56\%), clinical sepsis (45\%) and hemodialysis (33\%). On Kaplan-Meier analysis, patients with delayed-onset CMV disease had lower survival compared to patients without CMV disease identified during a hospitalization (Figure 1A). The survival curves diverged after approximately 1 year post-transplant. Patients with bacterial pneumonia, viral pneumonia and fungal pneumonia also had lower survival compared to patients without these conditions on Kaplan-Meier analysis (Figures 1B, 1C, 1D).

Univariate and multivariate Cox proportional hazard ratios for risk factors associated with inpatient death $>100$ days post-transplant are shown in Table 5. On multivariate analysis, delayed-onset CMV pneumonitis was associated with a $63 \%$ increased risk of death, whereas other types of CMV disease were not associated with death. Other risk factors for death identified on multivariate analysis were transplant failure or rejection $\left(\mathrm{HR}_{\mathrm{adj}} 2.5\right)$, bacterial pneumonia $\left(\mathrm{HR}_{\mathrm{adj}} 2.8\right)$, viral pneumonia $\left(\mathrm{HR}_{\mathrm{adj}} 1.5\right)$, fungal pneumonia $\left(\mathrm{HR}_{\mathrm{adj}}\right.$ $1.8)$, single lung transplant ( $\left.\mathrm{HR}_{\mathrm{adj}} 1.3\right)$ and idiopathic pulmonary fibrosis ( $\left.\mathrm{HR}_{\mathrm{adj}} 1.4\right)$. Delayed-onset CMV disease was associated with a 2-fold increased risk of death > 365 days post-transplant on univariate analysis (HR 95\% CI 1.5-2.8), and was marginally significant on multivariate analysis $\left(\mathrm{HR}_{\mathrm{adj}} 1.3,95 \% \mathrm{CI} 0.99-1.84\right.$, p-value $\left.=0.058\right)$. Delayed-onset CMV disease was not associated with an increased risk of death 101 to 365 days posttransplant.

\section{Discussion}

We conducted a retrospective cohort study of 1,528 adult lung transplant recipients from 2004 to 2010 using inpatient administrative billing data from 12 transplant centers located in 3 large and diverse states to determine the incidence, risk factors and outcomes associated with delayed-onset CMV disease coded during hospital readmission. 
We found that newly-coded CMV disease occurring > 100 days post-transplant was more common than early-onset CMV disease. This may reflect the widespread use of anti-CMV prophylaxis for at least 3 months after lung transplant ${ }^{11-14,20,21}$, thereby leading to a delay in the onset of CMV disease. Almost a quarter of new-onset CMV disease in this study population was coded as CMV pneumonitis. CMV pneumonitis in lung transplant recipients is well-described ${ }^{22-25}$, and is likely due to the predilection for CMV to involve the transplanted allograft ${ }^{3}$, as well as the large reservoir of latent CMV in lungs ${ }^{26}$ that can reactivate with increased immunosuppression.

Coding for transplant failure or rejection occurred in the majority of hospitalizations wherein CMV disease was identified, indicating a strong bidirectional relationship between allograft rejection and CMV replication ${ }^{6}$. Allograft rejection can result in increased inflammation, tumor necrosis factor (TNF) release and CMV transactivation ${ }^{27}$. Moreover, it typically leads to augmented immunosuppression which increases the risk of CMV disease ${ }^{5,28,29}$. Conversely, CMV replication can upregulate alloantigens ${ }^{30}$, and increase the expression of adhesion molecules that activate inflammatory cells in the allograft ${ }^{6}$, thereby promoting allograft rejection.

The only risk factor for delayed-onset CMV disease identified by our analysis was single lung transplantation. However, the association was small, and not adjusted for potential risk factors for CMV disease such as donor and recipient CMV serostatus ${ }^{31}$, type, timing and dose of immunosuppressive therapy $28,29,32$, or CMV prevention practices ${ }^{14,15}$. It is possible that native lung infections such as bacterial pneumonia and fungal infections result in increased inflammation ${ }^{33,34}$, thereby leading to transactivation of latent CMV in the transplanted lung and subsequent CMV disease ${ }^{26,27}$. The association between delayedonset CMV disease and single lung transplantation must be confirmed using clinical data.

Delayed-onset CMV pneumonitis (but not other types of CMV disease), was associated with an increased risk of death. Interestingly, death in these patients was not immediate, and occurred at a median of 7.8 months from the time of readmission with CMV disease. These results suggest that the effect of CMV pneumonitis on mortality is indirect, and an event such as bronchiolitis obliterans syndrome (BOS) may mediate the association between CMV pneumonitis and death. CMV pneumonitis has been reported to be associated with $\mathrm{BOS}{ }^{8-10}$, and BOS frequently causes death in lung transplant recipients ${ }^{2,7}$. It is possible that increased inflammation as a result of CMV replication and upregulation of proinflammatory chemokines in the lungs ${ }^{35}$ contributes to the development of BOS and death. Other risk factors for BOS include acute rejection ${ }^{7,36-41}$, pneumonia or bacterial airway colonization ${ }^{42}$, viral lower respiratory tract infections ${ }^{43-45}$, Aspergillus colonization of the lung allograft ${ }^{46}$ and single lung transplant ${ }^{47}$. We adjusted for these risk factors for BOS in multivariate analysis using coding for transplant failure or rejection, bacterial pneumonia, viral pneumonia, fungal pneumonia and single lung transplantation, and found that delayedonset CMV pneumonitis was independently associated with death. We could not assess the association between delayed-onset CMV disease and BOS directly since there is no specific ICD-9-CM code for BOS. Notably, delayed-onset CMV disease with no codes for CMV pneumonitis was not associated with death, suggesting milder illness such as asymptomatic viremia or CMV syndrome, or disease misclassification. 
Our study is the first to use a more representative cohort of lung transplant recipients with prolonged follow-up to determine the epidemiology of CMV disease, and contributes to our understanding of its incidence and outcomes. Moreover, it is the first study to demonstrate an association between delayed-onset CMV pneumonitis and an increased risk of death after adjusting for transplant failure or rejection, bacterial pneumonia, viral pneumonia, fungal pneumonia and single lung transplantation on multivariate analysis. It however has some limitations. The SID contain de-identified demographic and inpatient hospital ICD-9-CM billing data and do not have information on medications, laboratory test results or donor/ recipient CMV serostatus. Since the SID are de-identified, the data cannot be linked to more granular clinical data. Identification of comorbidities, risk factors and disease conditions depended on ICD-9-CM coding, which are not perfectly accurate ${ }^{48}$. There are no published data regarding the accuracy of CMV disease or CMV pneumonitis coding. Misclassification could have occured, though it likely would have resulted in more conservative estimates of the effect of CMV on mortality. Despite these limitations, this study contributes to our understanding of CMV disease in lung transplant recipients at the population level, and it clarifies the incidence and impact of delayed-onset CMV disease in the era of widespread use of anti-CMV prophylaxis after lung transplant.

In summary, we found using a large population of lung transplant recipients followed over a prolonged period of time that delayed-onset CMV disease coded during hospital readmission occurred more commonly than early-onset CMV disease. Moreover, we demonstrated that delayed-onset CMV pneumonitis is independently associated with an increased risk of death. Given the superiority of 12 months over 3 months of valganciclovir prophylaxis in preventing CMV disease among $\mathrm{D}+\mathrm{R}$ - and $\mathrm{R}+$ lung transplant recipients 14,15 , consideration should be given to administering extended valganciclovir prophylaxis to lung transplant recipients at risk of CMV disease. Future studies should assess the comparative effectiveness of extended versus short-course valganciclovir prophylaxis as they are used in clinical practice, and determining whether extended prophylaxis leads to a decreased risk of allograft failure and improved long-term survival.

\section{Acknowledgments}

We would like to acknowledge Phil Miller, Harini Subramaniam, Cherie Hill and Anita Hellstrom for help with statistical analysis, coding, database management and administrative support.

Funding: CAQ Santos is supported by the ICTS Multidisciplinary Clinical Research Career Development Program funded by NIH grant KL2 TR000450.

\section{References}

1. Zamora MR. Cytomegalovirus and lung transplantation. Am J Transplant. 2004; 4(8):1219-1226. [PubMed: 15268722]

2. Yusen RD, Christie JD, Edwards LB, et al. The Registry of the International Society for Heart and Lung Transplantation: Thirtieth Adult Lung and Heart-Lung Transplant Report--2013; focus theme: age. J Heart Lung Transplant. 2013; 32(10):965-978. [PubMed: 24054805]

3. Alexander BD, Tapson VF. Infectious complications of lung transplantation. Transpl Infect Dis. 2001; 3(3):128-137. [PubMed: 11493395]

4. Ljungman P, Griffiths P, Paya C. Definitions of cytomegalovirus infection and disease in transplant recipients. Clin Infect Dis. 2002; 34(8):1094-1097. [PubMed: 11914998] 
5. Razonable RR, Humar A. Cytomegalovirus in solid organ transplantation. Am J Transplant. 2013; 13(Suppl 4):93-106. [PubMed: 23465003]

6. Tolkoff-Rubin NE, Fishman JA, Rubin RH. The bidirectional relationship between cytomegalovirus and allograft injury. Transplant Proc. 2001; 33(1-2):1773-1775. [PubMed: 11267506]

7. Kroshus TJ, Kshettry VR, Savik K, John R, Hertz MI, Bolman RM III. Risk factors for the development of bronchiolitis obliterans syndrome after lung transplantation. J Thorac Cardiovasc Surg. 1997; 114(2):195-202. [PubMed: 9270635]

8. Estenne M, Maurer JR, Boehler A, et al. Bronchiolitis obliterans syndrome 2001: an update of the diagnostic criteria. J Heart Lung Transplant. 2002; 21(3):297-310. [PubMed: 11897517]

9. Snyder LD, Finlen-Copeland CA, Turbyfill WJ, Howell D, Willner DA, Palmer SM. Cytomegalovirus pneumonitis is a risk for bronchiolitis obliterans syndrome in lung transplantation. Am J Respir Crit Care Med. 2010; 181(12):1391-1396. [PubMed: 20167845]

10. Paraskeva M, Bailey M, Levvey BJ, et al. Cytomegalovirus replication within the lung allograft is associated with bronchiolitis obliterans syndrome. Am J Transplant. 2011; 11(10):2190-2196. [PubMed: 21794087]

11. Johansson I, Martensson G, Nystrom U, Nasic S, Andersson R. Lower incidence of CMV infection and acute rejections with valganciclovir prophylaxis in lung transplant recipients. BMC Infect Dis. 2013; 13:582. [PubMed: 24325216]

12. Zuk DM, Humar A, Weinkauf JG, Lien DC, Nador RG, Kumar D. An international survey of cytomegalovirus management practices in lung transplantation. Transplantation. 2010; 90(6):672676. [PubMed: 20581765]

13. Kotton CN, Kumar D, Caliendo AM, et al. International consensus guidelines on the management of cytomegalovirus in solid organ transplantation. Transplantation. 2010; 89(7):779-795. [PubMed: 20224515]

14. Palmer SM, Limaye AP, Banks M, et al. Extended valganciclovir prophylaxis to prevent cytomegalovirus after lung transplantation: a randomized, controlled trial. Ann Intern Med. 2010; 152(12):761-769. [PubMed: 20547904]

15. Finlen Copeland CA, Davis WA, Snyder LD, et al. Long-term efficacy and safety of 12 months of valganciclovir prophylaxis compared with 3 months after lung transplantation: a single-center, long-term follow-up analysis from a randomized, controlled cytomegalovirus prevention trial. J Heart Lung Transplant. 2011; 30(9):990-996. [PubMed: 21489817]

16. Singh N. Late-onset cytomegalovirus disease as a significant complication in solid organ transplant recipients receiving antiviral prophylaxis: a call to heed the mounting evidence. Clin Infect Dis. 2005; 40(5):704-708. [PubMed: 15714416]

17. Kumar D, Chernenko S, Moussa G, et al. Cell-mediated immunity to predict cytomegalovirus disease in high-risk solid organ transplant recipients. Am J Transplant. 2009; 9(5):1214-1222. [PubMed: 19422346]

18. Elixhauser A, Steiner C, Harris DR, Coffey RM. Comorbidity measures for use with administrative data. Med Care. 1998; 36(1):8-27. [PubMed: 9431328]

19. Schoenfeld, David. Partial Residuals for The Proportional Hazards Regression Model. Biometrika. 1982; 69(1):239-241.

20. Humar A, Kumar D, Preiksaitis J, et al. A trial of valganciclovir prophylaxis for cytomegalovirus prevention in lung transplant recipients. Am J Transplant. 2005; 5(6):1462-1468. [PubMed: 15888055]

21. Chmiel C, Speich R, Hofer M, et al. Ganciclovir/valganciclovir prophylaxis decreases cytomegalovirus-related events and bronchiolitis obliterans syndrome after lung transplantation. Clin Infect Dis. 2008; 46(6):831-839. [PubMed: 18269330]

22. Dauber JH, Paradis IL, Dummer JS. Infectious complications in pulmonary allograft recipients. Clin Chest Med. 1990; 11(2):291-308. [PubMed: 2189664]

23. Paradis IL, Williams P. Infection after lung transplantation. Semin Respir Infect. 1993; 8(3):207215. [PubMed: 8016481]

24. Ettinger NA, Bailey TC, Trulock EP, et al. Cytomegalovirus infection and pneumonitis. Impact after isolated lung transplantation. Washington University Lung Transplant Group. Am Rev Respir Dis. 1993; 147(4):1017-1023. [PubMed: 8385429] 
25. Ruttmann E, Geltner C, Bucher B, et al. Combined CMV prophylaxis improves outcome and reduces the risk for bronchiolitis obliterans syndrome (BOS) after lung transplantation. Transplantation. 2006; 81(10):1415-1420. [PubMed: 16732179]

26. Balthesen M, Messerle M, Reddehase MJ. Lungs are a major organ site of cytomegalovirus latency and recurrence. J Virol. 1993; 67(9):5360-5366. [PubMed: 8394453]

27. Docke WD, Prosch S, Fietze E, et al. Cytomegalovirus reactivation and tumour necrosis factor. Lancet. 1994; 343(8892):268-269. [PubMed: 7905100]

28. Hibberd PL, Tolkoff-Rubin NE, Conti D, et al. Preemptive ganciclovir therapy to prevent cytomegalovirus disease in cytomegalovirus antibody-positive renal transplant recipients. A randomized controlled trial. Ann Intern Med. 1995; 123(1):18-26. [PubMed: 7762909]

29. Conti DJ, Freed BM, Singh TP, Gallichio M, Gruber SA, Lempert N. Preemptive ganciclovir therapy in cytomegalovirus-seropositive renal transplants recipients. Arch Surg. 1995; 130(11): 1217-1221. [PubMed: 7487465]

30. Eid AJ, Razonable RR. New developments in the management of cytomegalovirus infection after solid organ transplantation. Drugs. 2010; 70(8):965-981. [PubMed: 20481654]

31. Schoeppler KE, Lyu DM, Grazia TJ, Crossno JT Jr, Vandervest KM, Zamora MR. Late-onset cytomegalovirus (CMV) in lung transplant recipients: can CMV serostatus guide the duration of prophylaxis? Am J Transplant. 2013; 13(2):376-382. [PubMed: 23205887]

32. Razonable RR, Rivero A, Rodriguez A, et al. Allograft rejection predicts the occurrence of lateonset cytomegalovirus (CMV) disease among CMV-mismatched solid organ transplant patients receiving prophylaxis with oral ganciclovir. J Infect Dis. 2001; 184(11):1461-1464. [PubMed: 11709790]

33. Mal H, Brugiere O, Sleiman C, et al. Morbidity and mortality related to the native lung in single lung transplantation for emphysema. J Heart Lung Transplant. 2000; 19(2):220-223. [PubMed: 10703700]

34. King CS, Khandhar S, Burton N, et al. Native lung complications in single-lung transplant recipients and the role of pneumonectomy. J Heart Lung Transplant. 2009; 28(8):851-856. [PubMed: 19632585]

35. Weigt SS, Elashoff RM, Keane MP, et al. Altered levels of CC chemokines during pulmonary CMV predict BOS and mortality post-lung transplantation. Am J Transplant. 2008; 8(7):15121522. [PubMed: 18513272]

36. Girgis RE, Tu I, Berry GJ, et al. Risk factors for the development of obliterative bronchiolitis after lung transplantation. J Heart Lung Transplant. 1996; 15(12):1200-1208. [PubMed: 8981205]

37. Husain AN, Siddiqui MT, Holmes EW, et al. Analysis of risk factors for the development of bronchiolitis obliterans syndrome. Am J Respir Crit Care Med. 1999; 159(3):829-833. [PubMed: 10051258]

38. Sharples LD, McNeil K, Stewart S, Wallwork J. Risk factors for bronchiolitis obliterans: a systematic review of recent publications. J Heart Lung Transplant. 2002; 21(2):271-281. [PubMed: 11834356]

39. Corris PA. Lung transplantation. Bronchiolitis obliterans syndrome. Chest Surg Clin N Am. 2003; 13(3):543-557. [PubMed: 13678312]

40. Hachem RR, Khalifah AP, Chakinala MM, et al. The significance of a single episode of minimal acute rejection after lung transplantation. Transplantation. 2005; 80(10):1406-1413. [PubMed: 16340783]

41. Burton CM, Iversen M, Carlsen J, et al. Acute cellular rejection is a risk factor for bronchiolitis obliterans syndrome independent of post-transplant baseline FEV1. J Heart Lung Transplant. 2009; 28(9):888-893. [PubMed: 19716040]

42. Valentine VG, Gupta MR, Walker JE Jr, et al. Effect of etiology and timing of respiratory tract infections on development of bronchiolitis obliterans syndrome. J Heart Lung Transplant. 2009; 28(2):163-169. [PubMed: 19201342]

43. Vilchez RA, Dauber J, McCurry K, Iacono A, Kusne S. Parainfluenza virus infection in adult lung transplant recipients: an emergent clinical syndrome with implications on allograft function. Am $\mathrm{J}$ Transplant. 2003; 3(2):116-120. [PubMed: 12603206] 
44. Kumar D, Erdman D, Keshavjee S, et al. Clinical impact of community-acquired respiratory viruses on bronchiolitis obliterans after lung transplant. Am J Transplant. 2005; 5(8):2031-2036. [PubMed: 15996256]

45. Khalifah AP, Hachem RR, Chakinala MM, et al. Respiratory viral infections are a distinct risk for bronchiolitis obliterans syndrome and death. Am J Respir Crit Care Med. 2004; 170(2):181-187. [PubMed: 15130908]

46. Weigt SS, Elashoff RM, Huang C, et al. Aspergillus colonization of the lung allograft is a risk factor for bronchiolitis obliterans syndrome. Am J Transplant. 2009; 9(8):1903-1911. [PubMed: 19459819]

47. Hadjiliadis D, Chaparro C, Gutierrez C, et al. Impact of lung transplant operation on bronchiolitis obliterans syndrome in patients with chronic obstructive pulmonary disease. Am J Transplant. 2006; 6(1):183-189. [PubMed: 16433773]

48. Rhodes ET, Laffel LM, Gonzalez TV, Ludwig DS. Accuracy of administrative coding for type 2 diabetes in children, adolescents, and young adults. Diabetes Care. 2007; 30(1):141-143. [PubMed: 17192348]

\section{Abbreviations}

AHA

AHRQ-HCUP

BOS

CMV

CI

aHR

ICD-9-CM

SID

UNOS
American Hospital Association

Agency for Healthcare Research and Quality Healthcare Cost and Utilization Project

Bronchiolitis obliterans syndrome

cytomegalovirus

confidence interval

adjusted hazard ratio

International Classification of Diseases, Ninth Revision, Clinical Modification

State Inpatient Databases

United Network for Organ Sharing 

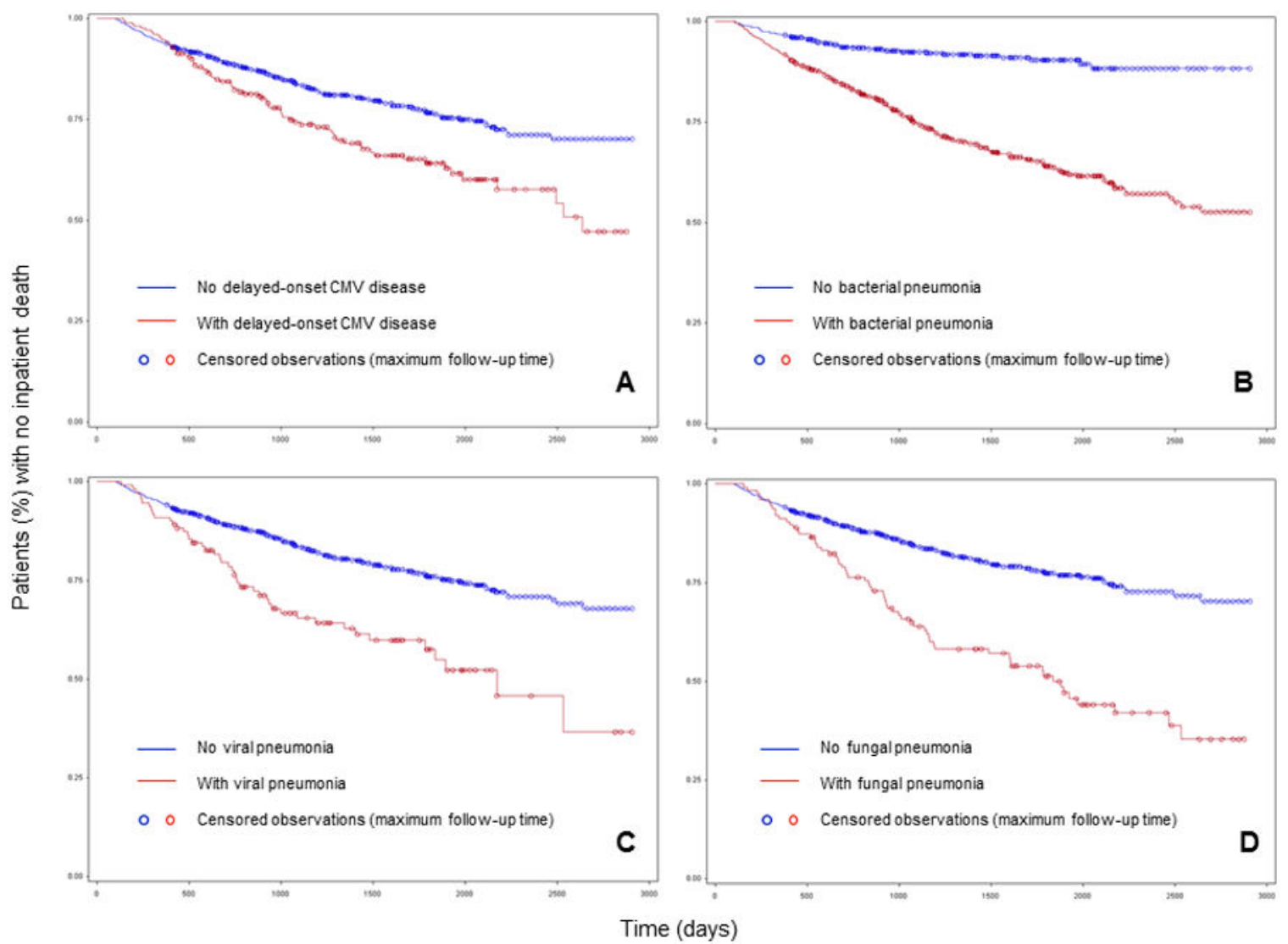

Figure 1.

Time (days) to inpatient death $>100$ days post-transplant in a cohort of adult lung transplant recipients, stratified according to presence or absence of delayed-onset CMV disease (A), bacterial pneumonia (B), viral pneumonia (C) and fungal pneumonia (D). 


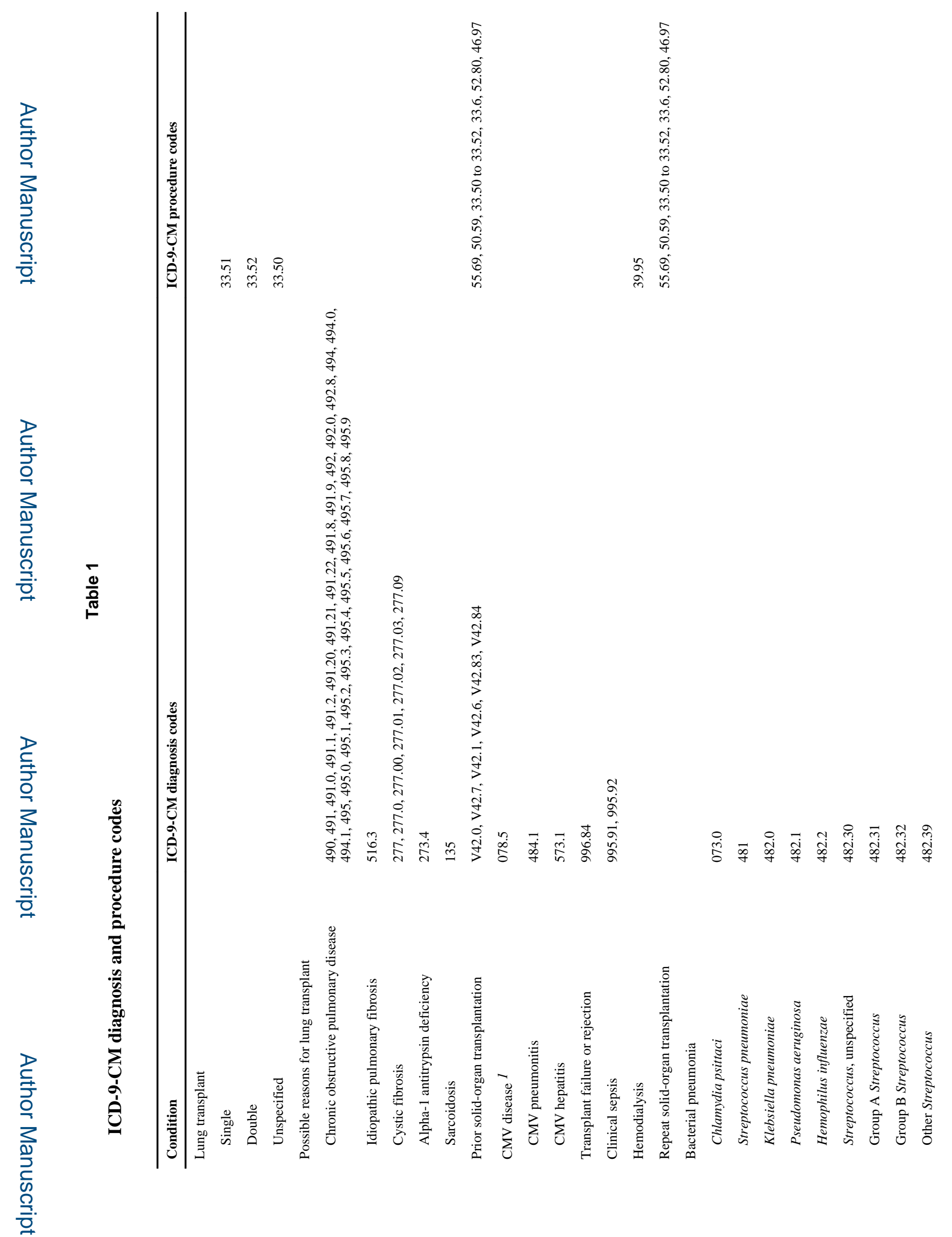

Transplantation. Author manuscript; available in PMC 2016 August 01. 
Santos et al.

Page 13

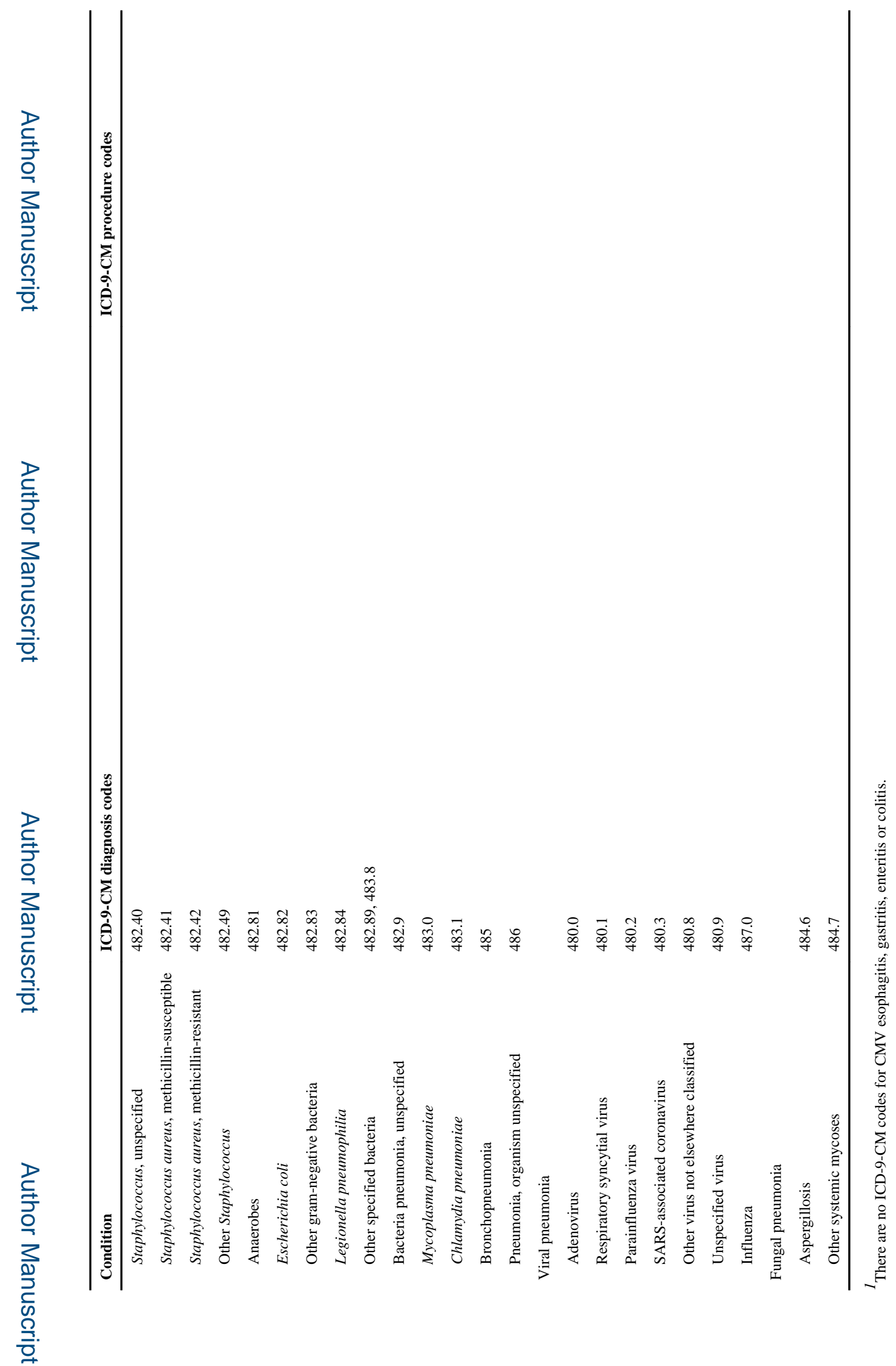

Transplantation. Author manuscript; available in PMC 2016 August 01. 
Table 2

Demographic and clinical characteristics of 1,528 lung transplant recipients at the time of organ transplantation

\begin{tabular}{|c|c|}
\hline Variables & All recipients \\
\hline \multicolumn{2}{|l|}{ Age, years } \\
\hline Mean + SD & $53.59+13.68$ \\
\hline Median (range) & $58(18-77)$ \\
\hline Female sex $(\%)$ & 41.82 \\
\hline \multicolumn{2}{|l|}{ Race $(\%)$} \\
\hline White & 76.90 \\
\hline Black & 5.69 \\
\hline Hispanic & 10.54 \\
\hline Asian or Pacific Islander & 3.01 \\
\hline Other or missing & 3.86 \\
\hline \multicolumn{2}{|l|}{ Patient location (urban-rural) (\%) 1} \\
\hline Large metropolitan & 71.07 \\
\hline Small metropolitan & 24.02 \\
\hline Micropolitan & 3.93 \\
\hline Not metropolitan or micropolitan, or missing & 0.98 \\
\hline \multicolumn{2}{|l|}{ Median income of patient ZIP code (\%) } \\
\hline First quartile (poorest) & 14.86 \\
\hline Second quartile & 20.16 \\
\hline Third quartile & 24.67 \\
\hline Fourth quartile (wealthiest) & 30.76 \\
\hline Missing & 9.55 \\
\hline \multicolumn{2}{|l|}{ Expected primary insurance payer $(\%)$} \\
\hline Medicare & 40.05 \\
\hline Private insurance & 49.74 \\
\hline Medicaid, self-pay, no charge, other or missing & 10.21 \\
\hline \multicolumn{2}{|l|}{ Type of lung transplant $(\%)$} \\
\hline Single & 34.03 \\
\hline Double or unspecified & 65.97 \\
\hline \multicolumn{2}{|l|}{ Possible reasons for lung transplant (\%) } \\
\hline Chronic obstructive pulmonary disease & 51.44 \\
\hline Idiopathic pulmonary fibrosis & 21.01 \\
\hline Cystic fibrosis & 16.30 \\
\hline Alpha-1 antitrypsin deficiency & 3.34 \\
\hline Sarcoidosis & 2.88 \\
\hline Other & 25.33 \\
\hline Prior transplant $(\%)$ & 3.99 \\
\hline Lung & 3.40 \\
\hline Other comorbidities (\%) & \\
\hline
\end{tabular}




\begin{tabular}{lr}
\hline Variables & All recipients \\
\hline Pulmonary circulation disease & 41.69 \\
Hypertension & 38.22 \\
Diabetes mellitus & 33.18 \\
Gastroesophageal reflux disease & 31.28 \\
Depression & 18.00 \\
Congestive heart failure & 10.86 \\
Valvular disease & 10.54 \\
Rheumatoid arthritis or collagen vascular disease & 8.57 \\
Hypothyroidism & 7.79 \\
Obesity & 7.46 \\
Neurologic disorders & 5.24 \\
Renal failure & 4.78 \\
Psychoses & 3.27 \\
Liver disease & 3.21 \\
Drug abuse & 2.68 \\
Peripheral vascular disease & 2.49 \\
Alcohol abuse & 2.16 \\
Duration of follow-up, years & \\
Mean & 3.2 \\
Median (interquartile range) & $-4.7)$ \\
Number of transplant centers & 12 \\
\hline
\end{tabular}

${ }^{1}$ Large metropolitan - at least 1 million residents; Small metropolitan - less than 1 million residents; Micropolitan - adjacent to large or small metropolitan area. 


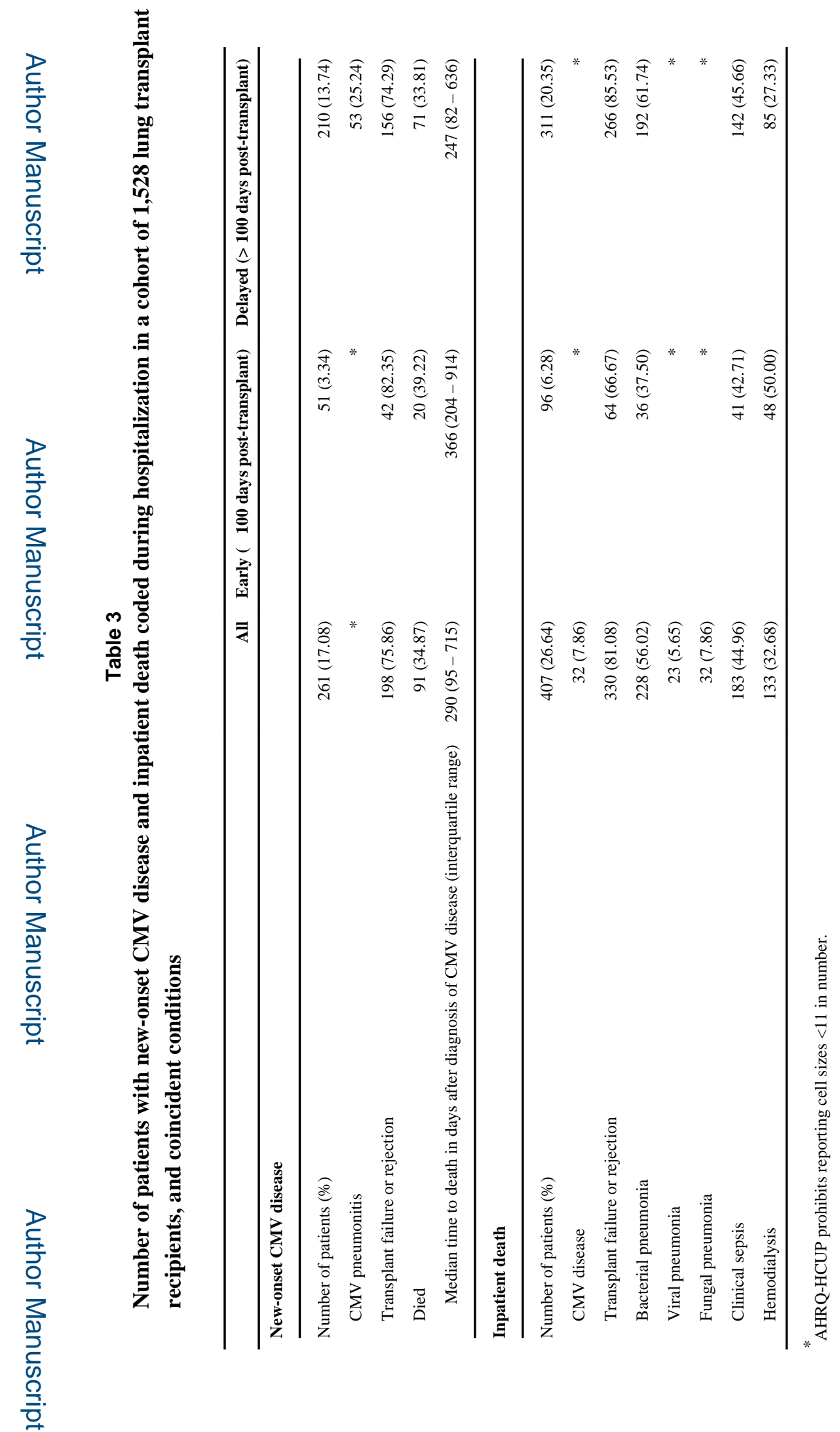

Transplantation. Author manuscript; available in PMC 2016 August 01. 


\section{로을}

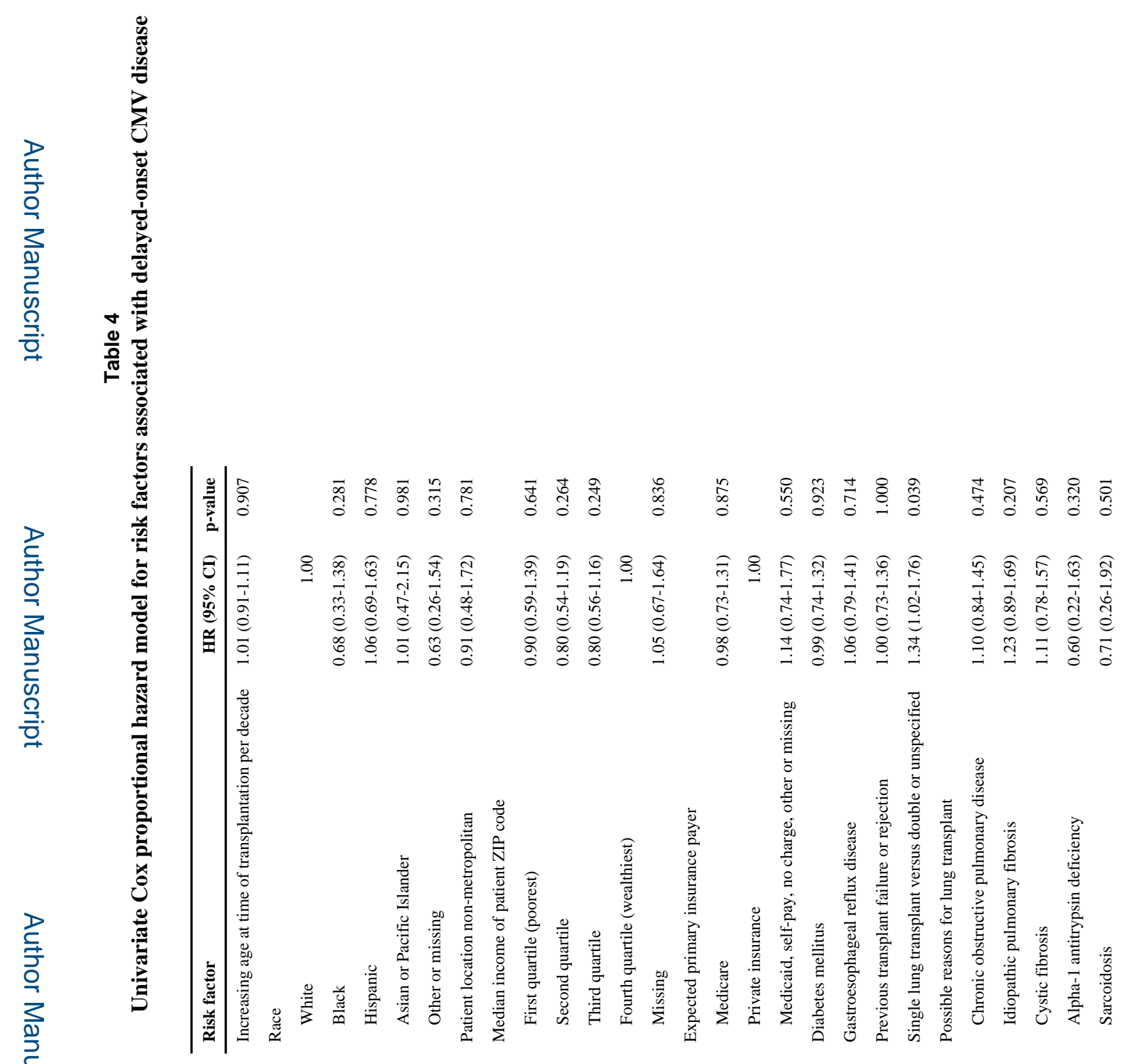




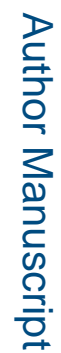

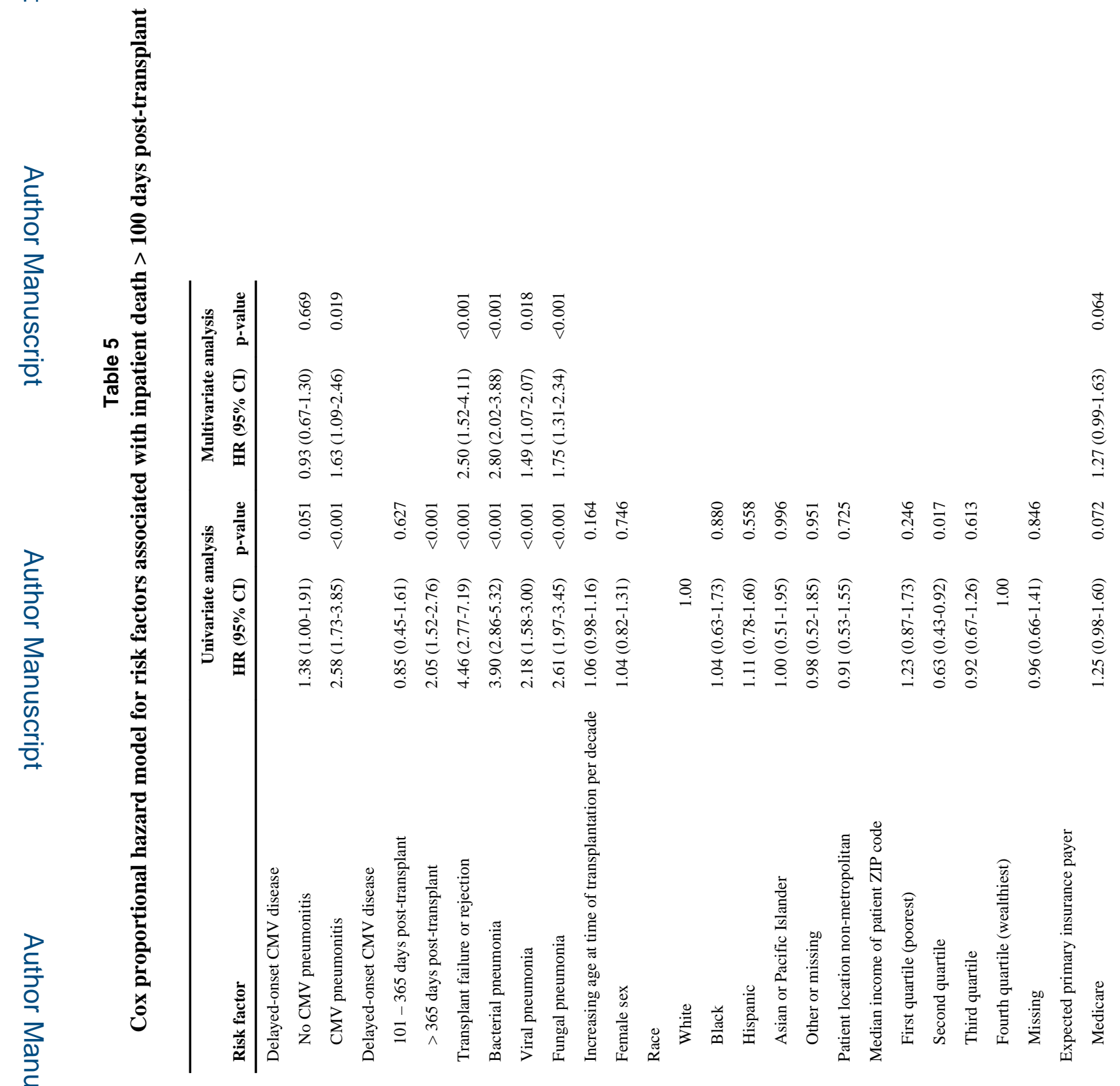




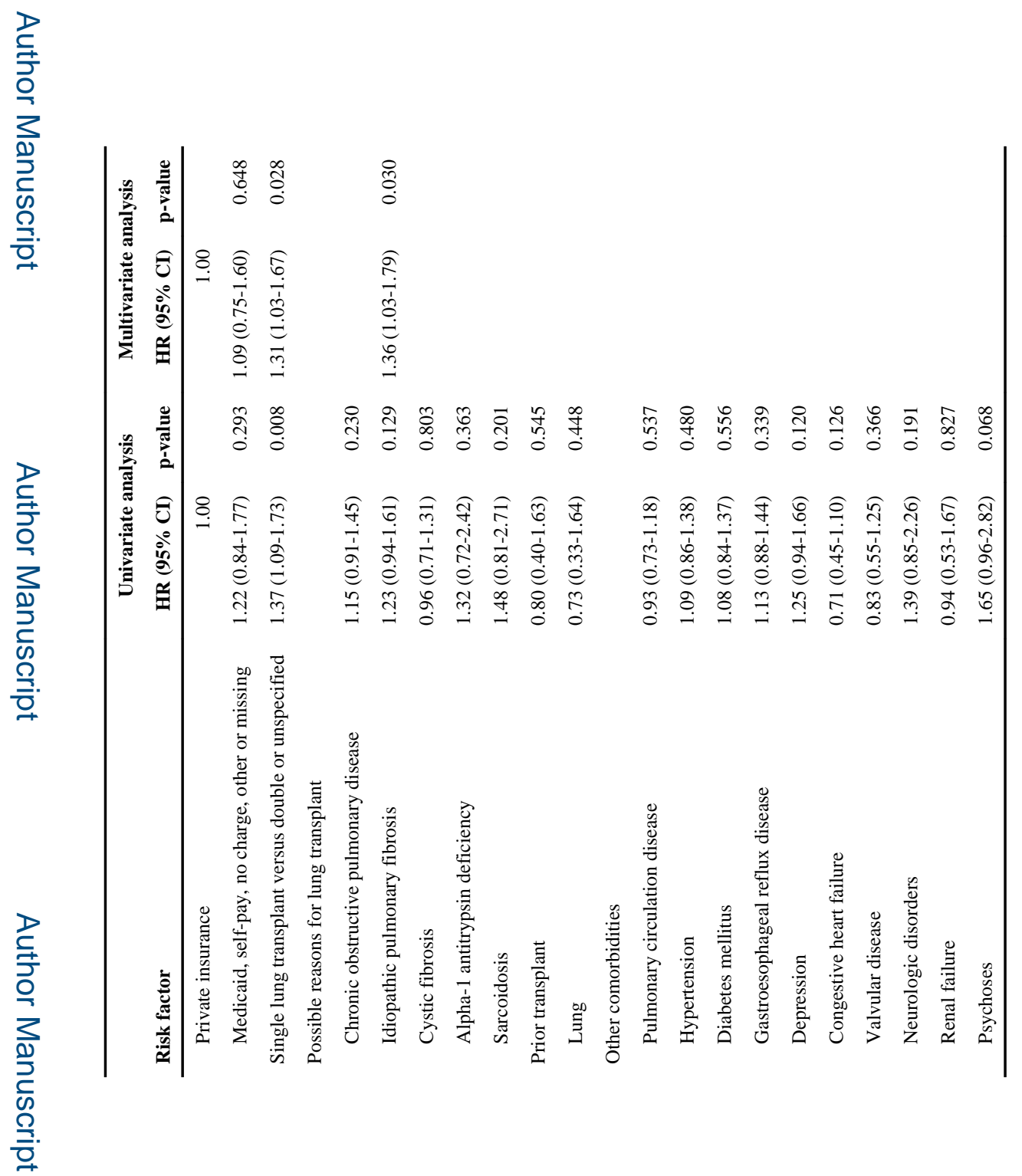

